\title{
The Effect of Antimony Substitution on the Magnetic and Structural Properties of $\mathrm{Fe}_{0.75-x} \mathrm{Si}_{0.25} \mathrm{Sb}_{x}$ Alloys
}

\author{
Imaddin A. Al-Omari ${ }^{*}$, M. R. Anantharaman ${ }^{2}$ \\ ${ }^{1}$ Department of Physics, Sultan Qaboos University, Muscat, Sultanate of Oman; ${ }^{2}$ Department of Physics, Cochin University of Sci- \\ ence and Technology, Cochin, India. \\ Email: *ialomari@squ.edu.om, ialomari@yahoo.com
}

Received December $28^{\text {th }}, 2011$; revised February $8^{\text {th }}, 2012$; accepted February $25^{\text {th }}, 2012$

\begin{abstract}
The results of the investigation of the magnetic and structural properties of the alloy system $\mathrm{Fe}_{0.75-x} \mathrm{Si}_{0.25} \mathrm{Sb}_{x}$, where $x=0$, $0.05,0.1,0.15,0.2$, and 0.25 synthesized by mechanical alloying followed by heat treatment are described. The $x$-ray diffraction reveals that all samples crystallize in the $\mathrm{DO}_{3}$-type cubic phase structure. Substituting Fe by Sb led to a decrease in the lattice constant and the unit cell volume. The magnetic properties are investigated by vibrating sample magnetometer and show that all the samples are ferromagnetically ordered at room temperature. The Curie temperature is found to decrease linearly from $(850 \pm 5) \mathrm{K}$ for the parent alloy to $(620 \pm 5) \mathrm{K}$ for the alloyith $x=0.25$. The saturation magnetizations at room temperature and at $100 \mathrm{~K}$ are found to decrease with increasing the antimony concentration. The above results indicate that $\mathrm{Sb}$ dissolves in the cubic structure of this alloy system.
\end{abstract}

Keywords: Lattice Constant; Curie Temperature; Saturation Magnetization

\section{Introduction}

Intermetallic compounds $\mathrm{Fe}_{3} \mathrm{X}(\mathrm{X}=\mathrm{Al}, \mathrm{Si}, \mathrm{Ge})$ are fascinating group of materials, which have recently attracted much attention from the viewpoint of fundamentals as well as application. This class of materials with the ordered phase at elevated temperatures $(T>800 \mathrm{~K})$ has promising mechanical and corrosion properties both in the microcrystalline and nanocrystalline states [1-4]. Ternary element additions to these systems have been used to improve the high temperature strength and other physical properties. At present, numerous experimental data are available on the ordered and disordered $\mathrm{Fe}_{3} \mathrm{Si}$ and $\mathrm{Fe}_{3} \mathrm{Al}$ alloy systems, because of their high temperature strength, excellent oxidation and corrosion resistance. Substitution of Fe by a transition metal element affects the magnetic properties, the lattice parameter, and the structural ordering of these alloys [5-12]. Waliszewski et al. [12] studied the $\mathrm{Fe}_{3-x} \mathrm{Cr}_{x} \mathrm{Si}$ system and found that the Curie temperature decreases from $840 \mathrm{~K}$ for $x=0$ to 712 $\mathrm{K}$ for $x=0.4$, and the magnetic moment of iron at the $\mathrm{B}$ site to be $2.44 \mu_{\mathrm{B}}$, and about $1.18 \mu_{\mathrm{B}}$ for $(\mathrm{A}, \mathrm{C})$ sites, while the magnetic moments of $\mathrm{Cr}$ were determined to be $(2.03 \pm 1.3) \mu_{\mathrm{B}}$ for $\mathrm{Cr}$ at the B site and $(0.41 \pm 0.63) \mu_{\mathrm{B}}$ for the $(\mathrm{A}, \mathrm{C})$ sites with orientation antiparallel to the magnetic moments of $\mathrm{Fe}$.

"Corresponding author.
The structural and magnetic properties of the intermetallic $\mathrm{Fe}-\mathrm{Si}$ alloys depend on the $\mathrm{Si}$ concentration. $\mathrm{FeSi}_{2}$ was found to form the tetragonal type structure, $\mathrm{FeSi}$ forms the $\mathrm{B} 20$ type structure, while $\mathrm{Fe}_{3} \mathrm{Si}$ forms the $\mathrm{DO}_{3}$ type cubic structure. $\mathrm{Fe}_{3} \mathrm{Si}$ is a well ordered ferromagnetic alloy with four sites: 2-equivanlt sites (A, C) occupied by $\mathrm{Fe}$ and the other two sites are occupied by $\mathrm{Fe}$ (B site) and $\mathrm{Si}$ (D site) [13]. $\mathrm{Fe}_{1-\gamma} \mathrm{Si}_{x}$ forms a continuous rage of solid solution with a bcc structure between $x=0$ and 0.265 [14]. Mössbauer and NMR [15,16] investigations for this system have yielded information about the hyperfine field and Si site occupation. These studies showed that the hyperfine field and the magnetic moment at the Fe sites strongly depend on the Si occupancy and the number of $\mathrm{Fe}$ nearest neighbors and they decrease with increasing the Si concentration.

A recent study by Mantovan et al. [4] showed that $\mathrm{Fe}_{3} \mathrm{Si}$ thin film is a good candidate as ferromagnetic electrode in spintronics devices due to its high spin polarization and Curie temperature. Furthermore, the use of $\mathrm{Fe}_{3} \mathrm{Si}$ has been proposed for spin injection in semiconductors [17]. Antimony is widely used in alloying to increase hardness and mechanical strength. Many of Antimony compounds are also used in superconductors, Hall-effect devices, diodes, batteries cable sheathing, tartar emetic which has been used in medicine. Prakash et al. [18] studied the effect of antimony doping on the transport and magnetic properties of $\mathrm{CeO}_{0.9} \mathrm{~F}_{0.1} \mathrm{FeAs}_{1-\chi} \mathrm{Sb}_{x}$ Super- 
conductors and found that $\mathrm{Sb}$ increases the superconducting transition temperature $\left(\mathrm{T}_{\mathrm{c}}\right)$ from $26 \mathrm{~K}$ for the parent compound with $x=0$ to $43.17 \mathrm{~K}$ for $x=0.1$. Antimony is the most effective additive to inhibit diffusional growth of particles. Dixon et al. [19] have shown that the addition of antimony to iron-in-mercury magnetic liquids forms a layer around the iron and reduces the growth of the nanoparticles which reduces the magnetization. The effect of antimony doping on magnetic properties of $\mathrm{Ni}-\mathrm{Zn}$ ferrites was studied by Purnanandam et al. [20]. This study confirmed that the magnetic quality factor increases with increasing $\mathrm{Sb}$ percentage while the saturation magnetization and the Curie temperature decrease with increasing antimony doping in $\mathrm{Ni}-\mathrm{Zn}$ ferrites.

In this paper we focused our attention on the synthesizes of the $\mathrm{Fe}_{0.75-\chi} \mathrm{Si}_{0.25} \mathrm{Sb}_{x}$ alloy system by mechanical alloying followed by heat treatment for six different samples which allows us to investigate the effects of substituting ferromagnetic iron be diamagnetic antimony on the structural and magnetic properties of the $\mathrm{Fe}_{0.75-x} \mathrm{Si}_{0.25} \mathrm{Sb}_{x}$ alloy system.

\section{Samples Preparation and Experimental Procedures}

$\mathrm{Fe}_{0.75-x} \mathrm{Si}_{0.25} \mathrm{Sb}_{x}$ alloys $(x=0,0.05,0.10,0.15,0.2$ and 0.25 ) were synthesized by mechanical alloying of high purity elemental $\mathrm{Fe}, \mathrm{Si}$, and $\mathrm{Sb}$ in a SPEX 8000 mixer/ mill for 15 hours using tungsten-carbide (WC) balls and WC vial. The ball to powder mass ratio was $3: 1$, and the milling was carried out under argon atmosphere. After the milling, the powder samples were annealed under vacuum in quartz ampoules for 24 hours at $800^{\circ} \mathrm{C}$, to ensure homogeneity. The ampoules were then rapidly quenched into cold water. Subsequent the samples were characterized by powder $x$-ray diffraction on a Philips diffractometer by using $\mathrm{Cu}-\mathrm{K}_{\alpha}$ radiation. The magnetic measurements were carried out in the temperature range $100 \mathrm{~K} \leq \mathrm{T} \leq 975 \mathrm{~K}$, using a Vibrating Sample Magnetometer (VSM) in magnetic fields up to $13.5 \mathrm{kOe}$.

\section{Results and Discussion}

Figure 1 shows the powder $x$-ray diffraction patterns for two representative samples of the alloy system

$\mathrm{Fe}_{0.75-x} \mathrm{Si}_{0.25} \mathrm{Sb}_{x}$ with $x=0.00$, and 0.15. All the observed reflection lines obtained at room temperature for all investigated samples exhibit lines characteristic for the $\mathrm{DO}_{3}$-type structure. The indices for the various peaks are shown in the diffraction patterns of Figure 1. All the other samples studied have similar behavior with a shift in the peaks' position. The patterns for each of the samples with $x$ between 0.00 and 0.25 are consistent with a single phase of the cubic type with lattice parameter $\mathrm{a}=$ $5.652 \AA$ for $x=0$. The composition dependence of the lattice constant $a$ on the $\mathrm{Sb}$ concentration are listed in
Table 1. The lattice parameter is found to decrease linearly with increasing the $\mathrm{Sb}$ concentration from $5.652 \AA$ for $x=0$ to $5.630 \AA$ for $x=0.25$. The lattice parameter a $=5.652 \AA$ for the parent alloy, with $x=0$, is in good agreement with previous reported values of $5.653 \AA$ by Cowdery and Kayser [21], and $5.650 \AA$ by Yoon and Booth [11]. The decrease in the lattice parameter and hence the unit cell volume with increasing the $\mathrm{Sb}$ concentration is due to the volume contraction because of the smaller atomic radius of $\mathrm{Sb}(1.53 \AA)$ compared with the atomic radius of $\mathrm{Fe}(1.72 \AA)$. This behavior is in good agreement with previous reported observations for similar alloys by Shobaki et al. [22] for $\mathrm{Fe}_{0.7-\chi} \mathrm{V}_{x} \mathrm{Al}_{0.3}$ alloys and Al-Omari and Hamdeh for $\mathrm{Fe}_{0.7-x} \mathrm{~V}_{x} \mathrm{Si}_{0.3}$ [23]. The linear decrease in the lattice parameter for these alloys as we increase the $\mathrm{Sb}$ concentration suggests a simple dilution process.

The magnetic field $(\mathrm{H})$ dependence of the magnetization (M) for the different samples at room temperature and at low temperature, $\mathrm{T}=100 \mathrm{~K}$, is shown in Figures 2 and 3. It is clear from these figures that all the samples exhibit ferromagnetic behavior with soft magnetic properties, as no hysteresis observed in any of the samples. The saturation magnetization $\left(\mathrm{M}_{\mathrm{s}}\right)$ for $\mathrm{Fe}_{0.75-x} \mathrm{Si}_{0.25} \mathrm{Sb}_{x}$ alloys as a function of the antimony concentration $(x)$, for

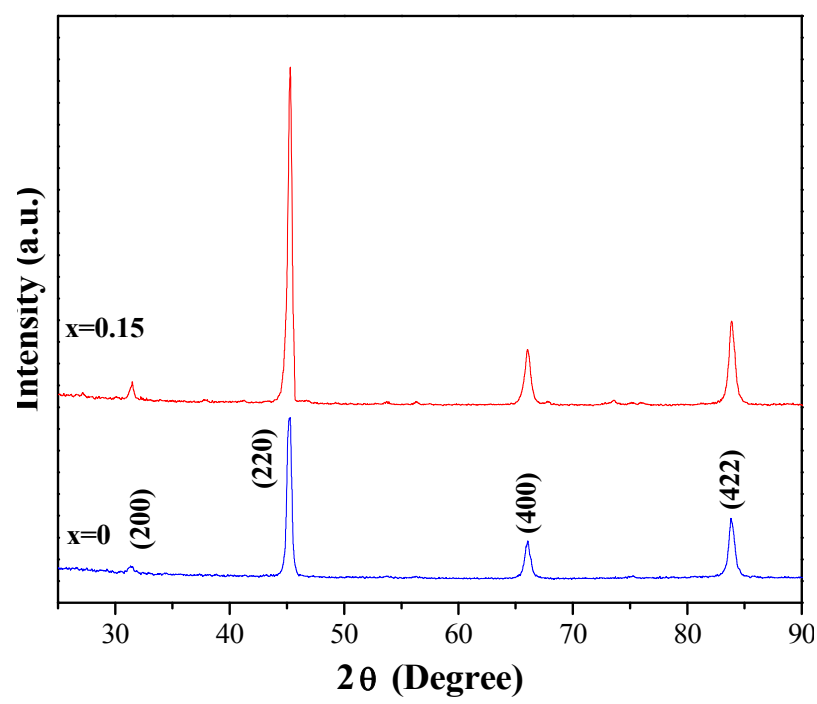

Figure 1. Typical $x$-ray diffraction pattern for two representative samples of the alloy system $\mathrm{Fe}_{0.75-x} \mathrm{Si}_{0.25} \mathrm{Sb}_{x}$.

Table 1. Dependence of the lattice constant (a) and the saturation magnetization at $T=0 \mathrm{~K}$ (found from the extrapolation) on the antimony concentration $(x)$, for $\mathrm{Fe}_{0.75-x} \mathrm{Si}_{0.25} \mathrm{Sb}_{x}$ alloys.

\begin{tabular}{lcccccc}
\hline$x$ & 0.00 & 0.05 & 0.10 & 0.15 & 0.20 & 0.25 \\
\hline$a(\AA ̊)$ & 5.652 & 5.649 & 5.644 & 5.639 & 5.635 & 5.630 \\
$\begin{array}{l}\mathrm{M}_{\mathrm{s}}(\mathrm{at} \mathrm{T}=0 \mathrm{~K}) \\
(\mathrm{emu} / \mathrm{g})\end{array}$ & 140.0 & 132.8 & 122.0 & 114.0 & 102.0 & 94.0 \\
\hline
\end{tabular}




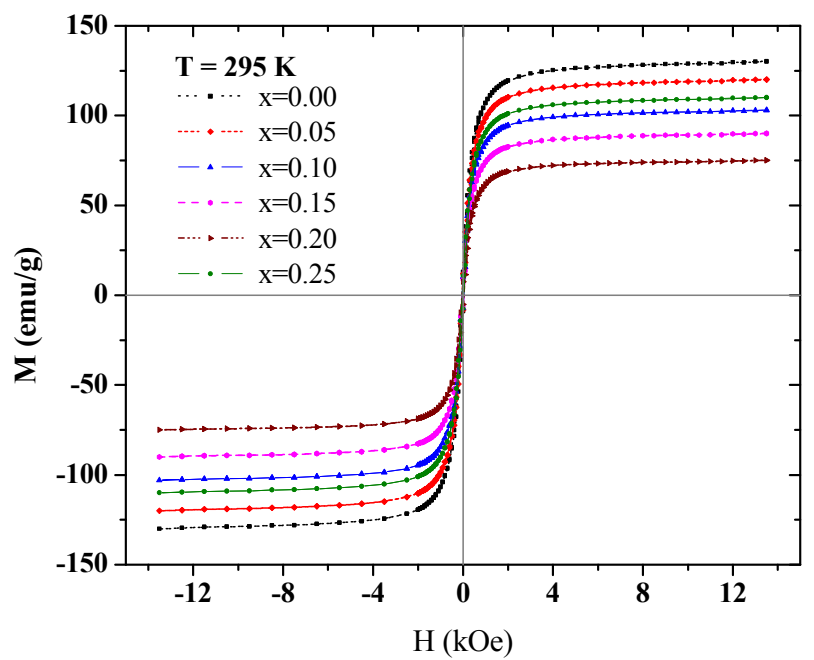

Figure 2. Magnetization curves for $\mathrm{Fe}_{0.75-x} \mathrm{Si}_{0.25} \mathrm{Sb}_{x}$ alloys, at room temperature for different antimony concentrations $(x)$.

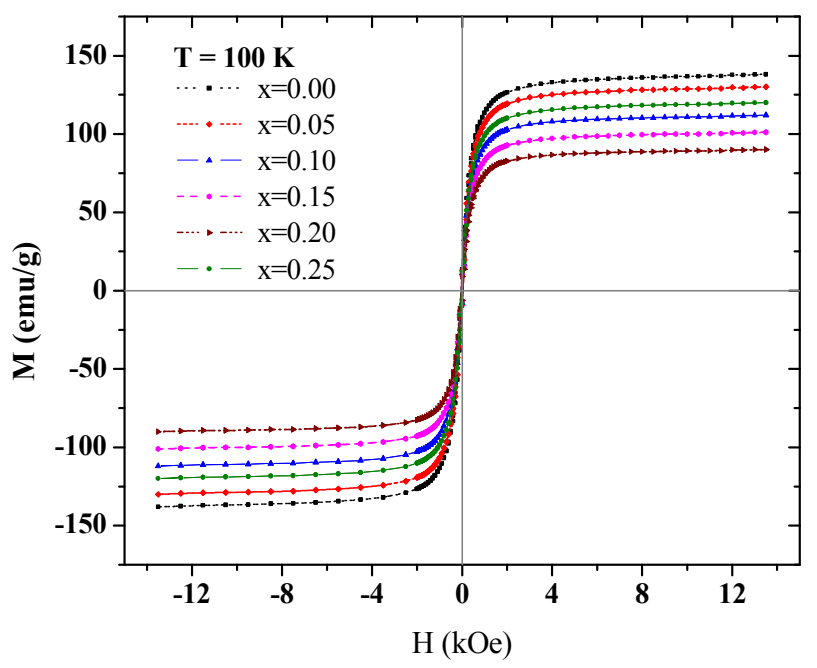

Figure 3. Magnetization curves for $\mathrm{Fe}_{0.75-x} \mathrm{Si}_{0.25} \mathrm{Sb}_{x}$ alloys, at low temperature $(T=100 \mathrm{~K})$ for different antimony concentrations $(x)$.

the two temperatures $\mathrm{T}=295 \mathrm{~K}$ and $\mathrm{T}=100 \mathrm{~K}$, is presented in Figure 4. As shown in this figure, $M_{s}$ decreases with increasing the $\mathrm{Sb}$ concentration $(x)$. This decrease is due to the replacement of ferromagnetic $\mathrm{Fe}$ by diamagnetic $\mathrm{Sb}$ in these alloys.

The temperature dependence of the magnetization for the different samples of the alloy system $\mathrm{Fe}_{0.75-x} \mathrm{Si}_{0.25} \mathrm{Sb}_{x}$ under an applied magnetic field of $13.5 \mathrm{kOe}$ is shown in Figure 5. It can be seen from this figure that all the samples studied have ferromagnetic ordering below Curie temperature $\left(\mathrm{T}_{\mathrm{c}}\right)$ while the spontaneous magnetization decreases with increasing the $\mathrm{Sb}$ concentration $(x)$. It is clear from Figure 5 that the magnetization increases with decreasing the temperature, as would be expected from a system with ferromagnetic coupling below $T_{c}$. This figure

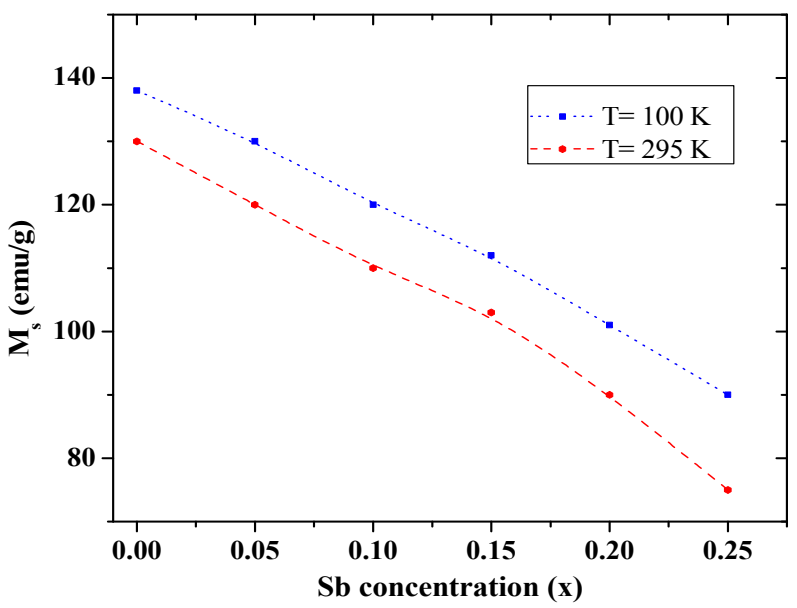

Figure 4. The saturation magnetization $\left(M_{s}\right)$ as a function of the antimony concentration $(x)$, at $T=295 \mathrm{~K}$ and $\mathrm{T}=100 \mathrm{~K}$, for $\mathrm{Fe}_{0.75-x} \mathrm{Si}_{0.25} \mathrm{Sb}_{x}$ alloys.

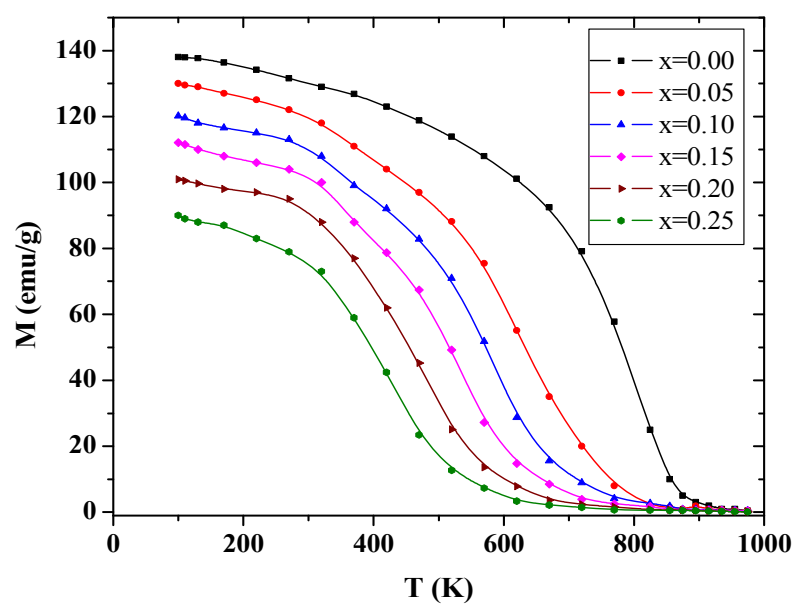

Figure 5. Temperature dependence of the magnetization for the different samples of the alloy system $\mathrm{Fe}_{0.75-x} \mathrm{Si}_{0.25} \mathrm{Sb}_{x}$ under an applied magnetic field of $13.5 \mathrm{kOe}$.

also shows that $M_{s}$ tends to decrease linearly with decreasing the temperature far below $T_{c}$. This decrease is expected for a system with ferromagnetic coupling and in qualitative agreement with our observation of the magnetic hyperfine field from the Mössbauer measurements on a similar $\mathrm{Fe}_{0.7-x} \mathrm{Si}_{0.3} \mathrm{Mn}_{x}$ alloy system [24].

Using the method of intersecting tangents for $M$ versus $\mathrm{T}$ curves in Figure 5, we found that the Curie temperature $T_{c}$ decreases linearly with increasing the antimony concentration and the results are shown in Figure 6. The Curie temperature of $(850 \pm 5) \mathrm{K}$ for $x=0$ is in agreement with other previously reported value of $840 \mathrm{~K}$ by Pugaczowa-Michalska et al. [25]. The decrease in $\mathrm{T}_{\mathrm{c}}$ with increasing $x$ can be attributed to the reduction of the exchange field interaction between the spins of the magnetic $\mathrm{Fe}$ atoms, which can be a result of the decrease of the number of magnetic atoms surrounding each iron atom upon increasing the $\mathrm{Sb}$ concentration. 


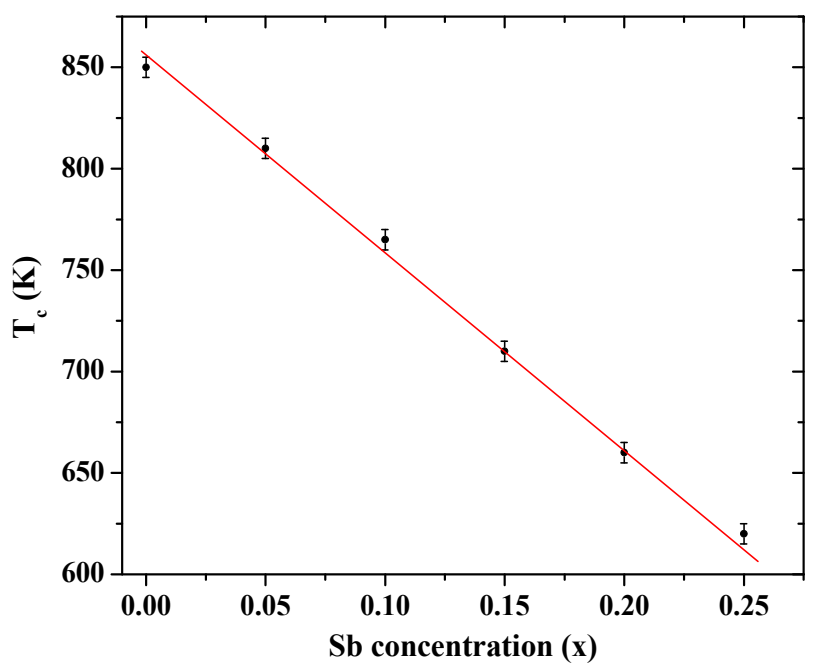

Figure 6. The Currie temperature $\left(T_{c}\right)$ as a function of on the antimony concentration $(x)$, for $\mathrm{Fe}_{0.75-x} \mathrm{Si}_{0.25} \mathrm{Sb}_{x}$ alloys. The solid line represents a guide to the eye.

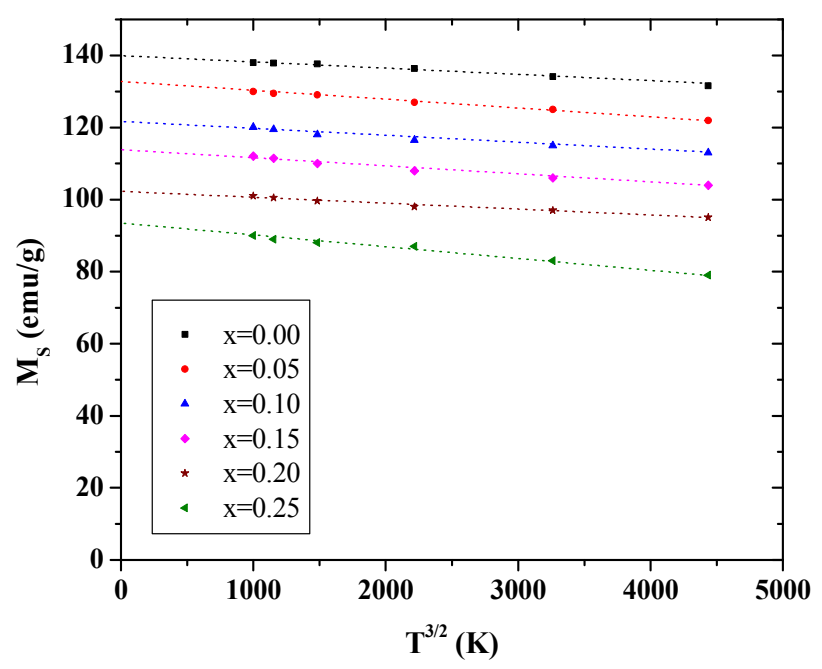

Figure 7. The saturation magnetization $\left(\mathrm{M}_{\mathrm{s}}\right)$ as a function of $\mathrm{T}^{3 / 2}$ (at low temperatures, $\mathrm{T} \leq 300 \mathrm{~K}$ ), for $\mathrm{Fe}_{0.75-x} \mathrm{Si}_{0.25} \mathrm{Sb}_{x}$ alloys. The solid lines represents a straight line extrapolated to $\mathbf{T}=\mathbf{0}$.

Since the magnetization of all the samples saturates for temperatures at room temperature and below we plotted in Figure 7 the saturation magnetization as a function of $\mathrm{T}^{3 / 2}$ at low temperatures $(\mathrm{T} \leq 300 \mathrm{~K})$, where $\mathrm{T}$ is the temperature in Kelvin. This figure shows that $\mathrm{M}_{\mathrm{s}}$ as a function of $\mathrm{T}^{3 / 2}$ obeys Bloch law at low temperatures, where by extrapolating $M_{s}$ to $T=0 \mathrm{~K}$ we can estimate the saturation magnetization at that temperature, and the results are presented in table I for the different $\mathrm{Sb}$ concentrations. The decrease in $\mathrm{M}_{\mathrm{s}}$ with increasing the antimony concentration, $x$, is due to the decrease in the iron magnetic moment due to replacing magnetic $\mathrm{Fe}$ by diamagnetic $\mathrm{Sb}$. The extrapolated saturation magnetization for $\mathrm{Fe}_{3} \mathrm{Si}$ at $\mathrm{T}$ $=0 \mathrm{~K}$ of $\left(140 \mathrm{emu} / \mathrm{g}=4.91 \mu_{\mathrm{B}} /\right.$ f.u. $)$ is in agreement with the calculated values of $5.1 \mu_{\mathrm{B}} /$ f.u. by PugaczowaMichalska et al. [25], $4.9 \mu_{\mathrm{B}} /$ f.u. by Kulikov et al. [26] and the experimental value of $4.7 \mu_{\mathrm{B}} / \mathrm{f}$.u. by Waliszewski et al. [12].

\section{Conclusion}

We have investigated the magnetic and structural properties of the alloy system $\mathrm{Fe}_{0.75-\chi} \mathrm{Si}_{0.25} \mathrm{Sb}_{x}$. Structural studies revealed the formation of the $\mathrm{DO}_{3}$-type cubic phase structure, with a decrease in the lattice constant and the unit cell volume upon substituting $\mathrm{Fe}$ by $\mathrm{Sb}$. Magnetic measurements showed that all the samples have ferromagnetic behavior up to the Curie temperature, $T_{c}$. The obtained linear dependence of the lattice constant, Curie temperature, and the saturation magnetization at low temperatures on the antimony concentration indicate a simple dilute solution when $\mathrm{Fe}$ is substituted by $\mathrm{Sb}$. All the results of the present work strongly suggest the reduction of the saturation magnetization with increasing $x$, which is due to the replacement of ferromagnetic $\mathrm{Fe}$ by diamagnetic $\mathrm{Sb}$.

\section{Acknowledgements}

The authors are grateful to Sultan Qaboos University for the support provided to perform this study under the research grant number IG/SCI/PHYS/09/01.

\section{REFERENCES}

[1] S. Sarkar, C. Bansal and A. Chatterjee, "Gibbs-Thomson Effect in Nanocrystalline Fe-Ge," Physical Review B, Vol. 62, No. 5, 2000, pp. 3218-3222. doi:10.1103/PhysRevB.62.3218

[2] Z. Q. Gao and B. Fultz, "Transient B32-Like Order during the Early Stages of Ordering in Undercooled $\mathrm{Fe}_{3} \mathrm{Al}$," Philosophical Magazine B, Vol. 67, No. 6, 1993, p. 787. doi:10.1080/13642819308219325

[3] S. Sarkar and C. Bansal, "Disorder-Order and Structural Phase Transformations in Nanocrystalline $\mathrm{Fe}_{3-x} \mathrm{Mn}_{x} \mathrm{Ge}$ Alloys Synthesized by Mechanical Alloying," Journal of Alloys and Compounds, Vol. 366, No. 1-2, 2004, pp. 107119.

[4] R. Mantovan, M. Georgieva, M. Fanciulli, A. Goikhman, N. Barantcev, Yu. Lebedinskil and A. Zenkevich, "Synthesis and Characterization of $\mathrm{Fe}_{3} \mathrm{Si} / \mathrm{SiO}_{2}$ Structures for Spintronics," Physica Status Solidi (A), Vol. 205, No. 8, 2008, pp. 1753-1757.

[5] K. Ishikawa, R. Kainuma, I. Ohnuma, K. Aoki and K. Ishida, "Phase Stability of the $\mathrm{X}_{2} \mathrm{AlTi}$ (X: Fe, Co, Ni and $\mathrm{Cu}$ ) Heusler and B2-Type Intermetallic Compounds," Acta Materialia, Vol. 50, No. 9, 2002, pp. 2233-2243. doi:10.1016/S1359-6454(01)00434-7

[6] S. Suga, S. Imada, A. Yamasaki, S. Ueda, T. Muro and Y. Saitho, "X-MCD at Twin-Helical Undulator Beam Line BL25SU of Spring-8," Journal of Magnetism and Mag- 
netic Materials, Vol. 233, No. 1-2, 2001, pp. 60-64. doi:10.1016/S0304-8853(01)00228-1

[7] G. L. F. Fraga, P. Pureur and D. E. Brandao, "Spontaneous Magnetoimpedance in the Heusler Compounds $\mathrm{Pd}_{2} \mathrm{MnSn}$ and $\mathrm{Pd}_{2} \mathrm{MnSb}$ near the Curie Temperature," Solid State Communications, Vol. 124, No. 1-2, 2002, pp. 7-10. doi:10.1016/S0038-1098(02)00476-3

[8] J. W. Dong, J. Lu, J. Q. Xie, L. C. Chen, R. D. James, S. Mckernan and C. J. palmstrom, "MBE Growth of Ferromagnetic Single Crystal Heusler Alloys on $\left(\begin{array}{lll}0 & 0 & 1\end{array}\right)$ $\mathrm{Ga}_{1-\chi} \mathrm{In}_{x}$ As," Physica E, Vol. 10, No. 1-3, 2001, pp. 428432. doi:10.1016/S1386-9477(01)00131-X

[9] G. A. Al-Nawashi, S. H. Mahmood, A. D. Lehlooh and A. S. Saleh, "Mössbauer Spectroscopic Study of Order-Disorder Phenomena in $\mathrm{Fe}_{3-x} \mathrm{Mn}_{x} \mathrm{Si}$," Physica B, Vol. 321, No. 1-4, 2002, pp. 167-172. doi:10.1016/S0921-4526(02)00845-1

[10] Y. Kobayashi, T. Kaneko, M. Kamogawa, K. Asai, K. Akiyama and H. Funakubo, "Structural Characterization by Electronic Transport Properties on $\mathrm{Fe}_{3} \mathrm{Si}$ Films," Journal of Physics D: Applied Physics, Vol. 40, No. 22, 2007, pp. 6873-6878. doi:10.1088/0022-3727/40/22/003

[11] S. Yoon and J. Booth, "Magnetic Properties and Structures of Some Ordered (FeMn) $)_{3} \mathrm{Si}$ Alloys," Journal of Physics F: Metal Physics, Vol. 7, No. 6, 1977, pp. 10791095. doi:10.1088/0305-4608/7/6/022

[12] J. Waliszewski, L. Dobrzynski, A. Malinowski, D. Satula, K. Szmanski, W. Prandl, Th. Brückel and O. Schärpf, "Magnetic Moment Distribution in $\mathrm{Fe}_{3-x} \mathrm{Cr}_{x} \mathrm{Si}$ Alloys," Journal of Magnetism and Magnetic Materials, Vol. 132, No. 1-3, 1994, pp. 349-358. doi:10.1016/0304-8853(94)90331-X

[13] V. A. Niculescu, T. J. Burch and J. I. Budnick, “A Local Environment Description of Hyperfine Fields and Atomic Moments in $\mathrm{Fe}_{3-x} \mathrm{~T}_{x} \mathrm{Si}$ Alloys," Journal of Magnetism and Magnetic Materials, Vol. 39, No. 3, 1983, pp. 223-267. doi:10.1016/0304-8853(83)90084-7

[14] M. Hansen, "Constitution of Binary Alloys," McGrawHill, New York, 1958.

[15] M. B. Stearns, "Internal Magnetic Fields, Isomer Shifts, and Relative Abundances of the Various Fe Sites in FeSi Alloys," Physical Review, Vol. 129, No. 3, 1963, pp. 1136-1144. doi:10.1103/PhysRev.129.1136

[16] J. J. Budnick, S. Skalski, T. J. Burch and J. H. Wernick, "Hyperfine Fields in Fe-Si Alloys," Journal of Applied Physics, Vol. 38, No. 3, 1967, pp. 1137-1138. doi:10.1063/1.1709514

[17] A. Ionescu, C. A. F. Vaz, T. Trypiniotis, C. M. Gütler, H.
García-Miquel, J. A. C. Bland, M. E. Vickers, R. M. Dalgliesh, S. Langridge, Y. Bugoslavsky, Y. Miyoshi, L. F. Cohen and K. R. A. Ziebeck, "Structural, Magnetic, Electronic, and Spin Transport Properties of Epitaxial $\mathrm{Fe}_{3} \mathrm{Si} /$ GaAs(001)," Physical Review B, Vol. 71, No. 9, 2005, pp. 1-9. doi:10.1103/PhysRevB.71.094401

[18] J. Prakash, S. J. Singh, G. Thakur, S. Patnaik and A. K. Ganguli, "The Effect of Antimony Doping on the Transport and Magnetic Properties of $\mathrm{Ce}(\mathrm{O} / \mathrm{F}) \mathrm{FeAs}$," Superconductor Science and Technology, Vol. 24, No. 12, 2011, Article ID 125008. doi:10.1088/0953-2048/24/12/125008

[19] T. S. Dixon, S. W. Charles and J. Popplewell, "The Effect of the Addition of Antimony on the Physical and Magnetic Properties of Iron Particles in Mercury," Journal of Physics F: Metal Physics, Vol. 11, No. 9, 1981, pp. 19311941. doi:10.1088/0305-4608/11/9/022

[20] M. Purnanandam, T, Bhimasankaram and S. V. Suryanarayana, "Effect of Antimony Doping on Magnetic Properties of Ni-Zn Ferrites," Journal of Materials Science, Vol. 26, No. 22, 1991, pp. 6131-6134. doi:10.1007/BF01113895

[21] S. Cowdery and F. Kayser, "Lattice Parameters of Ferromagnetic $\mathrm{DO}_{3}$-Structured Iron-Aluminum-Silicon Alloys," Materials Research Bulletin, Vol. 14, No. 1, 1979, pp. 9199. doi:10.1016/0025-5408(79)90236-8

[22] J. Shobaki, I. A. Al-Omari, M. K. Hassan, B. A. Albiss, K. A. Azez, M.-Ali Al-Akhras, H. H. Hamdeh and S. H. Mahmood, "Mössbauer and Structural Studies of $\mathrm{Fe}_{0.7-x} \mathrm{~V}_{x} \mathrm{Al}_{0.3}$ Alloys," Journal of Magnetism and Magnetic Materials, Vol. 213, No. 1-2, 2000, pp. 51-55. doi:10.1016/S0304-8853(99)00621-6

[23] I. A. Al-Omari and H. H. Hamdeh, "Mössbauer and Structural Studies of $\mathrm{Fe}_{0.7-x} \mathrm{~V}_{x} \mathrm{Si}_{0.3}$ Alloy System," Physica Status Solidi (C), Vol. 1, No. 7, 2004, pp. 1809-1812.

[24] I. A. Al-Omari, A. Gismelseed, A. Rais, H. M. Widatallah, A. Al-Rawas, M. Elzain and A. A. Yousif, "Mössbauer Studies of $\mathrm{Fe}_{0.7-\chi} \mathrm{Si}_{0.3} \mathrm{Mn}_{x}$ Alloys," Hyperfine Interactions, Vol. 156-157, No. 1-4, 2004, pp. 123-127. doi:10.1023/B:HYPE.0000043233.23660.69

[25] M. Pugaczowa-Michalska, A. Go, L. Dobrzynski and S. Lipinski, "Electronic Structure and Magnetism of $\mathrm{Fe}_{3-x} \mathrm{Cr}_{x} \mathrm{Si}$ Alloys," Journal of Magnetism and Magnetic Materials, Vol. 256, No. 1-3, 2003, pp. 46-53. doi:10.1016/S0304-8853(02)00295-0

[26] N. I. Kulikov, D. Fristot, J. Hugel and A. V. Postnikov, "Interrelation between Structural Ordering and Magnetic Properties in bcc Fe-Si Alloys," Physical Review B, Vol. 66, No. 1, 2002, Article ID 014206. doi:10.1103/PhysRevB.66.014206 